\title{
Development of technology for water purification by filtration using vibration
}

\author{
Nikolai Serpokrylov ${ }^{1, *}$, Alla Smolyanichenko ${ }^{1,2}$, and Vladimir Nelidin ${ }^{1}$ \\ ${ }^{1}$ Don State Technical University, 1, Gagarin Sq., 344003, Rostov-on-Don, Russia \\ ${ }^{2}$ The State Maritime University named after Admiral F.F. Ushakov, 8, Sedova St., 344006, Rostov- \\ on-Don, Russia
}

\begin{abstract}
Improving the quality of water treatment is accompanied by an increase in technology requirements. An important role in solving problems of technological ensuring the quality of treatment, among which a prominent place is occupied by filtration methods, biological, chemical and mechanical methods. Among the mentioned cleaning methods, mechanical cleaning methods and one of its varieties are widely used, a new model - water purification by filtration using vibration technology.
\end{abstract}

\section{Introduction}

Along with a certain analogy of the method of vibration cleaning with other widely known and practiced methods of cleaning media, vibration cleaning of media has exceptional characteristics that are not characteristic of alternative ones, so when applying vibration cleaning of media [1]:

1) the purification of the medium proceeds uniformly, and its intensity is more stable;

2) there is an alternation of the working conditions of the treatment (separation, destruction of solid phases, clarification, liquid purification, etc.) due to the intermittent nature of their interaction with certain conditions of cleaning parameters;

3 ) the presence of vibrations increases the speed of cleaning certain tasks;

4) due to the necessary conditions, the cleaning of the environment is more intensive.

The method of vibrational cleaning of media is a complex of interrelated phenomena in which the deformation of solid phases, the activation of particles in different ranges of the cleaning medium, the formation and destruction of secondary structures, repeated with the frequency of the disturbing force, are involved [2-6].

The intensity during vibration cleaning depends on the intensity of the mechanical and chemical effects and the ability of a particular composition of the cleaning medium to resist the effects of these processes.

\section{Materials and Methods}

In the process of vibration cleaning, the media to be cleaned are loaded into a working chamber filled with a working medium of the required characteristics. Further, a working

*Corresponding author: arpis-2006@mail.ru 
chamber mounted on elastic elements (for example, springs) and having the ability to oscillate in different directions, is informed by vibration from an inertial vibrator with a frequency of $15-50 \mathrm{~Hz}$ and an amplitude of $0.5-9 \mathrm{~mm}$.

In the process of vibrating, the working medium is continuously subjected to accelerations of varying sign, they come into intensive relative movement, making two kinds of movements: the oscillations of each particle and the rotation of the entire mass (circulation motion). From the walls of the working chamber, vibration is transmitted to adjacent particles of the working medium, which transmit it to the following particles, etc.

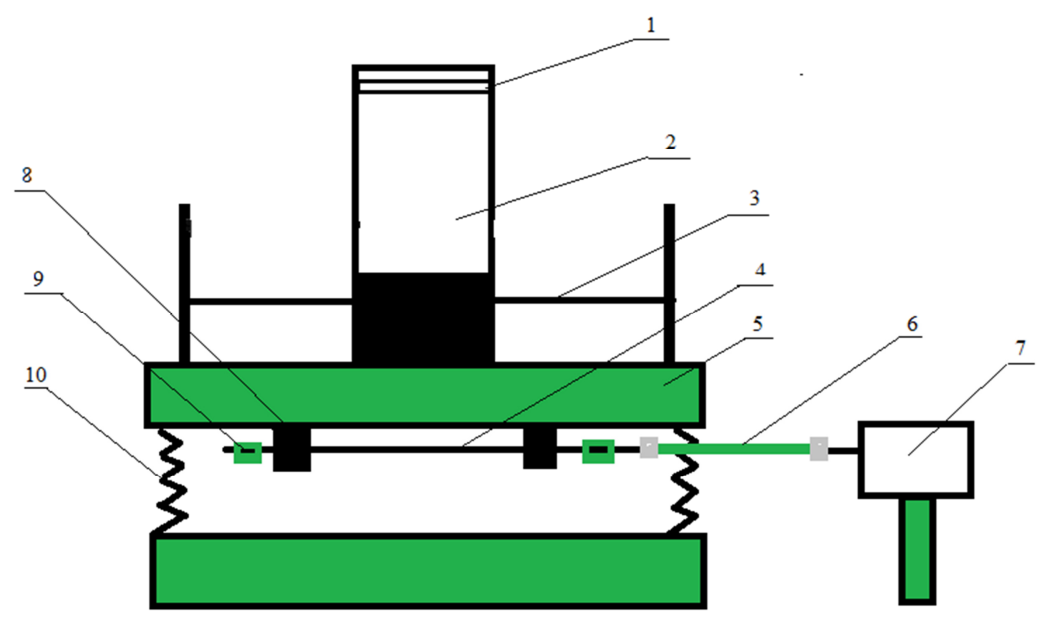

Fig. 1. Scheme of the vibration cleaning process: 1 - lid of the working chamber; 2 - working chamber (cylindrical flask); 3 - flexible mounts; 4 - shaft; 5 - platform; 6 - flexible coupling; 7 electric motor; 8 - bearing; 9 - unbalance; 10 - springs.

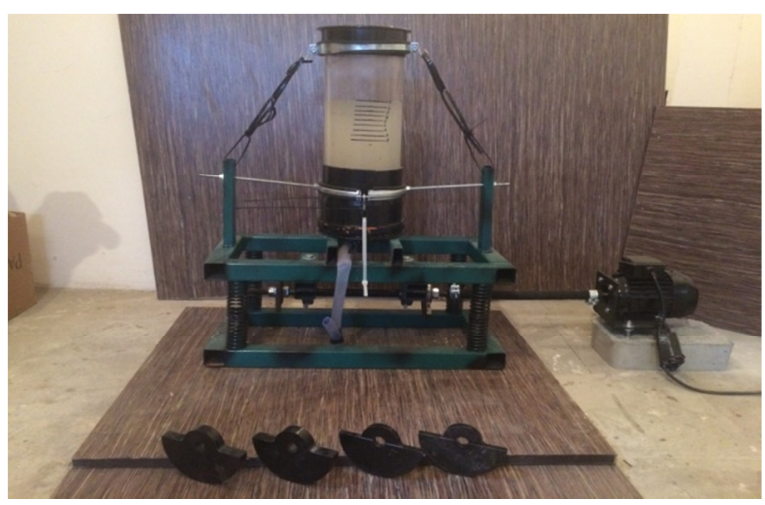

Fig. 2. General view of the laboratory installation of vibration cleaning.

During the cleaning process, the medium occupies positions in the working chamber, which ensures uniform cleaning of the entire volume. The impact of vibration on the cleaning medium has a large number of microshocks in various directions, helping to keep it in suspension, thus eliminating the slowdown of the cleaning process [7-10].

Under the influence of vibrations, cleaning occurs relatively evenly at all points of the working chamber. The processing at the top is somewhat more effective, where the amplitude of the oscillation of the working medium is higher. As you move down from the walls of the working chamber, the amplitude of oscillations of the particles of the working medium and the cleaning intensity are less effective. 
When controlling the parameters of the amplitude of the oscillation on the volume of the working chamber, the cleaning intensity in its various zones varies significantly.

The processing process is carried out mainly with periodic or continuous supply into the working chamber of the technological fluid of the required composition and also dry materials. By adjusting the liquid level in the working chamber, the processing intensity is controlled. Various types of chemical additives with special properties can be introduced into the composition of the process fluid, which makes it possible to control the intensity of the process or the quality of treatment.

Depending on the purpose of the operation, materials of various characteristics, as well as metallic and non-metallic filter materials of the required shape and size, can be used as working media

The intensity of vibration cleaning depends on the mode and duration of processing, characteristics and volume of the working chamber, dimensions of the working chamber and its degree of filling, mechanical properties of the material being cleaned, and other features [11-13].

The most common parameters of the vibration process are the force of impacts (microimpacts) and the characteristics of the particles of the working medium. Among the main parameters of vibrational cleaning, one should mention the nature of the movement (trajectory) of the working chamber and particles of the working medium, their speed and acceleration, the force of microshocks, contact pressure. The numerical values of these parameters are as follows: the velocity of the particles of the medium can reach $0.5-1 \mathrm{~m} / \mathrm{s}$; acceleration is $20-150 \mathrm{~m} / \mathrm{s}^{2}$, the power of micro-impacts is $1.5-3 \mathrm{kgf}$, the contact pressures arising from this can reach $700-1500 \mathrm{kgf} / \mathrm{mm}^{2}$, the average temperature in the working chamber usually does not exceed $30-40{ }^{\circ} \mathrm{C}$.

In the process of vibration cleaning, the working chamber performs harmonic (and (or) close to them) vibrations, while its points move along the trajectory in the form of a circle, cylinder and (or) ellipse. Particles of the working medium during each period of oscillations in a certain section of it move together with the working chamber, and during this period their trajectories and speeds coincide or are extremely close. Then there is a separation of the particles of the medium from the walls of the working chamber due to the difference in their speeds and accelerations, after which the particles of the medium make free movement (flight). In fact, in this section of the period of oscillations, the path of motion of the particles of the medium is complex and uncertain [14-16].

During each oscillation period, the working medium encounters and leaves (throws) the working medium from the walls of the working chamber, periodically loosens it, moves particles of the working medium along some walls of the working chamber along with the walls of the working chamber.

The amplitude of the oscillations in most cases varies between 0.5-5 mm. Much less often, it reaches 7-8 mm., Allow fluctuations with an amplitude of up to $15-20 \mathrm{~mm}$ at a relatively low frequency of oscillations $(5-15 \mathrm{~Hz})$.

The oscillation frequency for the main VI circuit reaches $15-50 \mathrm{~Hz}$.

\section{Results}

Clay solution (50 g per 1 liter of water), placed in a working chamber, was used for cleaning. The amplitude of the oscillations was controlled by adjusting the unbalanced pairs. The shaft rotation speed is constant $(600 \mathrm{rpm})$ at a frequency of $25 \mathrm{~Hz}$.

Initially, the cleaning medium (clay + water) was mixed within 2 to 3 minutes; transparency values - $4 \mathrm{~mm}$ (relative to the upper layer of the medium); the optimal processing time was $\mathrm{t}=5 \mathrm{~min}$; as a measuring device of the clarification indicator, a home- 
made device was used (a curved wire of the desired shape); processing was carried out in the range of 5-30min; working chamber oscillation mode: $\mathrm{A}=08-1 \mathrm{~mm} ; \mathrm{f}=25 \mathrm{~Hz}$. The experimental results are presented in table. 1 and in Fig. 3.

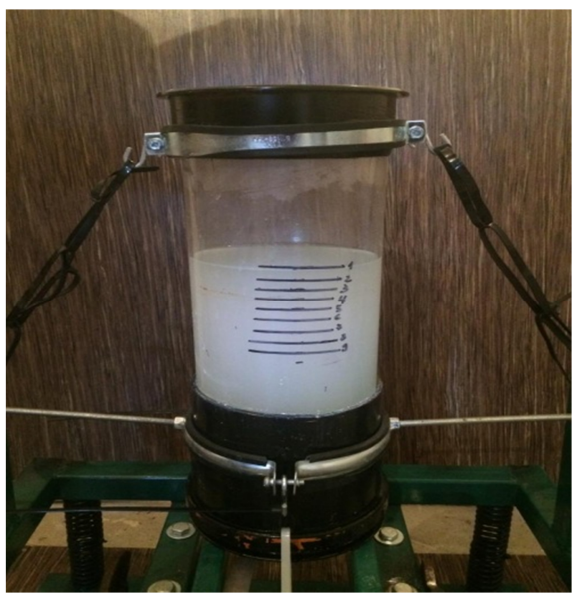

Fig. 3. Model solution for clarification on a vibrating installation.

Table 1. The results of an experiment to clarify a model solution in a vibrating installation.

\begin{tabular}{|c|c|c|}
\hline $\mathrm{t}, \min$ & Level, cm & Range $(\mathrm{t}, \mathrm{min})$ \\
\hline 0 & 4 & $12: 50$ \\
\hline 5 & 8 & $12: 55$ \\
\hline 10 & 10 & $13: 00$ \\
\hline 15 & 11 & $13: 05$ \\
\hline 20 & 11 & $13: 10$ \\
\hline 25 & 11 & $13: 15$ \\
\hline
\end{tabular}

Technical characteristics of the vibration unit:

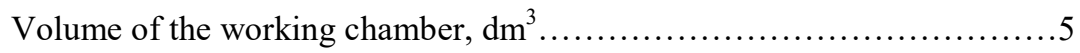

Number of working chambers, pcs ...................................... 1

Vibration Platform System......................................................unbalanced

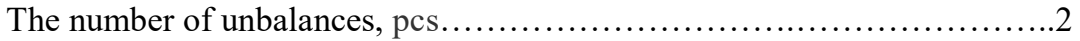

Vibration amplitude, mm........................................................

Oscillation frequency, Hz................................................15,25

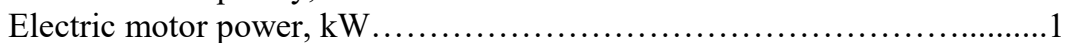

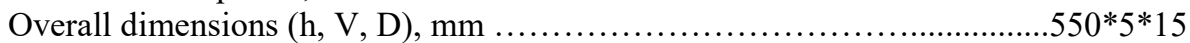

An electric motor was used as a source of shaft rotation.

In fig. Figure 3 presents the results of the experiment of vibrational cleaning of clarification of the working medium, showing a significant increase in the intensity of the process with vibration of the working medium (for a range of t 5-10 min), the cleaning time in this case is not relevant.

For comparison, Fig. 4 and Table 2 show the results of the experiment of clarification of the working medium without the use of vibrational cleaning. The process was carried out by waiting in time (precipitate). 


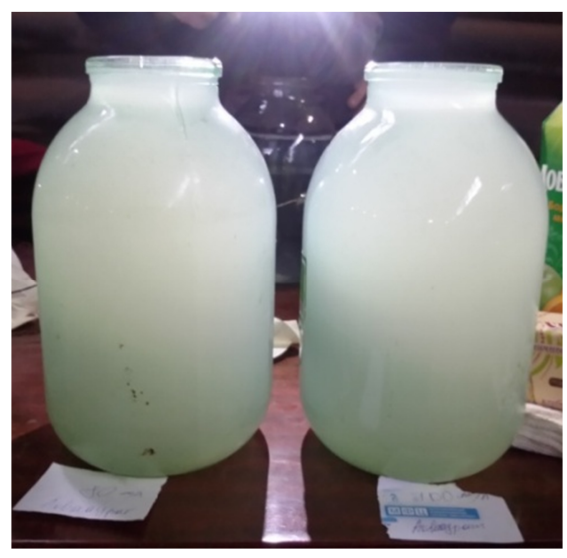

Fig. 4. Model solution during clarification by deposition.

Table 2. The results of the experiment on the clarification of the model solution by deposition.

\begin{tabular}{|c|c|c|}
\hline$t$, min & Level, cm & Range (t, min) \\
\hline 0 & 4.7 & $14: 37$ \\
\hline 5 & 5.5 & $14: 52$ \\
\hline 10 & 6 & $14: 57$ \\
\hline 15 & 6.3 & $15: 02$ \\
\hline 20 & 6.6 & $15: 07$ \\
\hline 25 & 7.1 & $15: 13$ \\
\hline
\end{tabular}
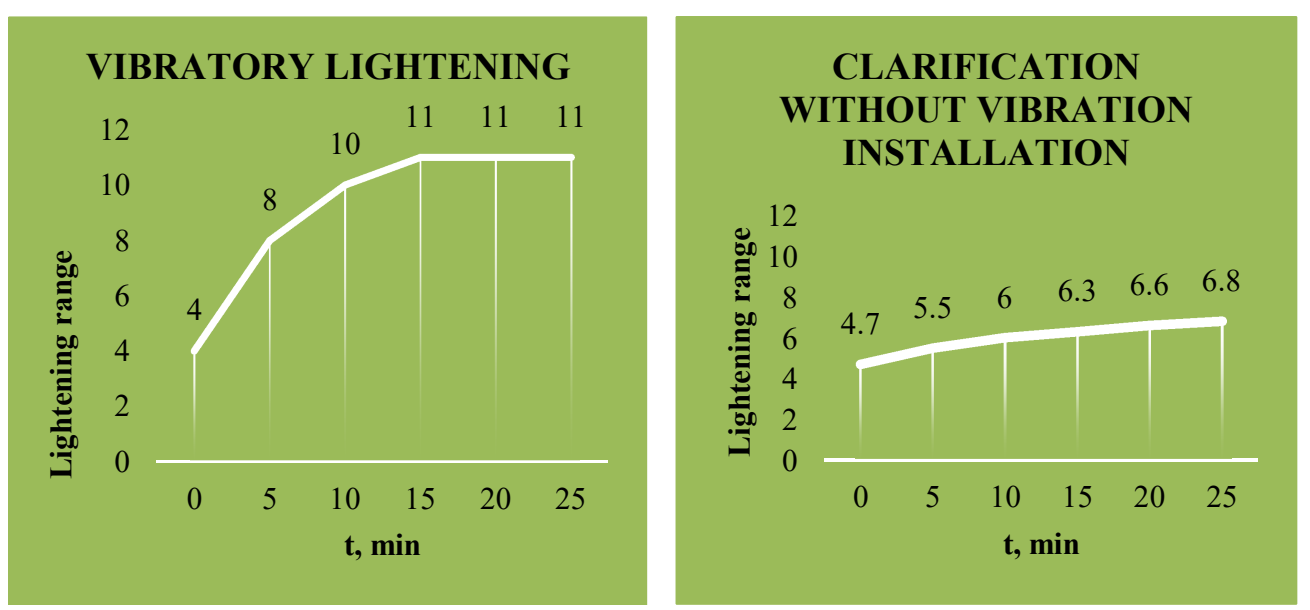

Fig. 5. Graphical representation of experiments

\section{Discussion}

The collision velocity of the particles of the medium is determined by the well-known empirical formula:

$$
\begin{gathered}
V_{\text {h.p.c. }}=V_{p . k .} \cdot K V \\
K_{v}=a^{\prime}=0,9877^{\prime}
\end{gathered}
$$


where $V_{\text {p.k. }}$ - the speed of movement of the working chamber, determined by the formula

$$
V=\sqrt{A_{y}^{2} \omega^{2} \sin ^{2} \omega t+a_{x}^{2} \cos ^{2} \omega t}
$$

or by a simplified formula

$$
\begin{gathered}
V=A \cdot \omega \\
\text { when } \omega=\frac{2 \pi n}{60}=\frac{n}{10} \\
V=\frac{A n}{10}
\end{gathered}
$$

$\mathrm{Kv}$ - speed loss coefficient; A and $\omega$ - respectively, the amplitude and angular frequency of oscillations; $\mathrm{t}$ - time; Ax, Ay - value of the amplitude of oscillations in the coordinates $\mathrm{X}$ and $\mathrm{Y} ; 1$ - distance from the wall of the working chamber to the point in question (medium particles).

The accelerations of colliding bodies during VI can reach $15-150 \mathrm{~m} / \mathrm{s}^{2}$ and are determined by the formula

$$
\begin{gathered}
a=A \omega^{2} \sin (\omega t+\phi) \\
a \max =A \omega^{2}
\end{gathered}
$$

As a general parameter of the process of vibrational cleaning, the collision forces of medium particles are considered, while science and scientists proposed relatively complex equations for their (collision forces of medium particles) definitions. Impact forces during vibrational cleaning vary widely depending on the mode of oscillation and the characteristics of the working medium, reaching both $0.5 \mathrm{kgf}$ and $5 \mathrm{kgf}$, not excluding large values. In practice, equations are known for calculating its values, including:

When processing freely loaded materials and liquid mixtures:

$$
F_{c b}=\sqrt[6]{\frac{m_{1} v_{s}^{2} \sigma_{s} R_{b} K_{m} K_{g} K}{K_{2}} B}
$$

where $\mathrm{m}_{\mathrm{i}}$ - reduced mass of a medium particle; Vs - collision speed; Rb - ball radius; $\sigma_{\mathrm{S}}$ yield strength of the material of the processed medium; $K$ - recovery ratio; $K_{2}, K_{m}, K_{g}$ empirical coefficients, characterizing respectively: repeated impacts of particles in one place, simultaneous action of particles of the medium, damping properties of the medium upon impact; B is a coefficient determining the amount of collision energy.

Analysis of the experimental results shows a significant increase in the intensity of the process during vibration cleaning of the working environment, which is explained by an increase in the speed of the process and the quality of the result.

In this article, the regularities of the process are investigated, the boundaries (limits) of the applied modes of vibration cleaning are established, while the process parameters are achieved - productivity and quality.

\section{Conclusions}

A promising direction in the field of industrial wastewater treatment is the use of technologies with intensive exposure to the treated fluid with minimal energy costs and a 
high degree of purification. Equipment that implements such technologies includes devices with vibrating mechanical action, operating in resonant mode.

Using the resonance phenomenon can significantly increase the efficiency of energy use for processing liquids (organic substances (or) media).

The use of the resonance phenomenon can significantly increase the energy efficiency for processing liquids and gases. The method of vibration exposure can be used as a complex for mechanical, acoustic and chemical treatment used at various stages of wastewater treatment contaminated with hydrophobic contaminants

The method of vibration exposure can be used as a complex for mechanical, acoustic and chemical treatment used at various stages of wastewater treatment contaminated with hydrophobic contaminants.

Based on the results of theoretical and experimental studies, a new technological scheme for the vibrational cleaning of media (organic substances) has been developed.

Additional parameters for controlling the intensity of the process are established in the form of an adjustable frequency and amplitude of oscillation.

Based on the results of the experimental work, a installation of vibrational cleaning of media was developed, during the operation of which positive qualitative characteristics were identified, due to which the goal of the work was achieved - increasing the intensity of the process of vibration cleaning based on an adjustable installation process of a cleaning medium.

\section{References}

1. M.R. Doosti, R. Kargar, M.H. Sayadi, Pro Łeedings of the International A ademy of $E\lceil$ ology and Environmental $S\lceil$ ien es 2(2), 96-110 (2012)

2. L.N. Fesenko, E.D. Khetsuriani, D.S. Larin, IOP Conference Series: Materials Science and Engineering 262 (2017) https://iopscience.iop.org/article/10.1088/1757$899 \mathrm{X} / 262 / 1 / 012174$

3. M.M. Sangadzhiev, V.A. Onkaev, A.N. Badrudinova, Journal of environmental management and tourism Romania 5(21), 1024-1032 (2017)

4. A.A. Dordzhiev, A.G. Dordzhiev, V.A. Onkaev, Journal of Environmental Management and Tourism. Biannually VIII 5(21), 130-135 (2018)

5. I. Aftanaziv, L. Shevchuk, S. Malovanyy, L. Strutynska, I. Samsin, J. Ecol. Eng. 20(6), 141-152 (2019)

6. S. Bilokon, Y. Turba, N. Kunanets, V. Pasichnyk, Econtechmod. an international quarterly journal 8(2), 21-26 (2019)

7. S. Denisov, E. Gordeef, S. Maksimov, Procedia Engineering 150, 2387 - 2391 (2016)

8. E. Akhondi, F. Zamani, K.H. Tng, G. Leslie, W.B. Krantz, A.G. Fane, J.W. Chew, Applied. Science 7, 765 (2017)

9. V.A. Devisilov, E.Yu. Sharai, IOP Conf. Series: Earth and Environmental Science 408, 012016 (2020)

10. Liu Ming-kai, Liu Ying-ya, Bao Dan-dan, Zhu Gen, Yang Guo-hai, Geng Jun-feng, Li Hai-tao, Sci Reports 7, 43717 (2017)

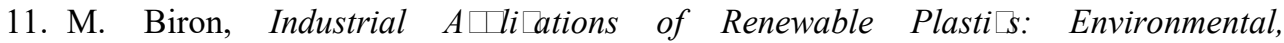
Te \hnologi $\llbracket$ al, and $E\lceil$ onomi $\square$ Advan $\llbracket$ es (Elsevier, 2017)

12. V.K. Gupta, I. Ali, Environmental Water. Advan $\lessdot e s$ in Treatment, Remediation and $\operatorname{Re}\lceil$ y ling (Elsevier, Oxford, 2003)

13. A.S. Smolyanichenko, A.S. Khalil, IOP Conference Series: Materials and 
Technologies in Construction and Architecture 698, 970-973 (2019) https://iopscience.iop.org/article/10.1088/1757-899X/698/2/022072/pdf

14. A.I. Zouboulis, E.N. Peleka, A. Ntolia, Separations 6(2), 20 (2019) https://doi.org/10.3390/separations6020020

15. R.A. Andersen, J.A. Berges, P.J. Harrison, Algal $\square$ ulturing te $\not$ hniques (Elsevier Academic Press, 2005)

16. A.S. Khalil1, S.V. Starovoytov, N.S. Serpokrylov, IOP Conference Series: Materials and Technologies in Construction and Architecture 931, 979-984 (2018) https://www.scientific.net/MSF.931.979 